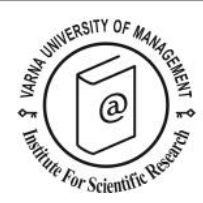

\title{
Accessible tourism: origins, state of the art and future lines of research
}

\author{
Lucía Rubio-Escuderos¹, Hugo García-Andreu² and Javier Ullán de la Rosa ${ }^{3 *}$
}

\footnotetext{
${ }^{1}$ Instituto Universitario de Investigaciones Turísticas, Sociología I. University of Alicante, Spain. E-mail: luciarubio.e@gmail.com/lre5@alu.ua.es

${ }^{2}$ Instituto Universitario de Investigaciones Turísticas, Sociología I. University of Alicante, Spain. E-mail: hugo.andreu@ua.es

3 Instituto Universitario de Desarrollo Social y Paz, Sociología II. University of Alicante, Spain. E-mail: javier.ullan@gcloud.ua.es

* Corresponding author
}

\begin{abstract}
Accessible tourism (AT) is a quite young and evolving research field. This paper provides an original review of the most significant academic literature on AT. Through a narrative method called 'qualitative systematic review', this article contextualizes the emergence of AT, identifies the applied methods and theories, the main research lines and the latest advances in the field. Further, we analysed the impact of disability's change of conception on the evolution of AT studies. The results reveal a considerable increase from 2007 onwards of the themes covered by publications on AT and a greater influence of the biopsychosocial model. Studies implementing experimental methodologies or theoretical approaches are more frequent in the last decade. We also identified shared limitations that are hindering the advance of knowledge on AT, such as the excessive use of qualitative sampling in surveys or the recurrence of similar social circles for the selection of participants. The complexity of disability as a physical and social phenomenon is a challenge to be addressed in the future of AT studies. This paper contributes by providing an AT literature review grounded in its social context, which allows us to identify future trends and avenues of research and turn current limitations into valuable proposals.
\end{abstract}

Keywords: accessible tourism; qualitative systematic review; theoretical foundations; disabilities; themes; research limitations

Citation: Rubio-Escuderos, L., García-Andreu, H. and Ullán de la Rosa, J. (2021). Accessible tourism: origins, state of the art and future lines of research. European Journal of Tourism Research 28, 2803.

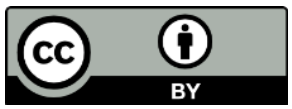




\section{Introduction. The concept of Accessible Tourism (AT)}

The first definition of AT referred to the process of removing the barriers that preclude impaired people from fully enjoying a tourist experience (Buhalis \& Darcy, 2011; UNWTO, 2016). Currently it has evolved to include the process of reshaping the whole tourist environment (regarding physical, informative, online, attitudinal aspects, etc.) in accordance with the Universal Design ${ }^{1}$ to allow its use by all population groups, regardless of their age, condition, capacity or impairment (Buhalis \& Darcy, 2011; Buhalis \& Michopoulou, 2011; UNWTO, 2016). The emergence of AT is inseparably related to two epochal processes brought about by the advent of postmodern/postindustrial societies. On the one hand, the emergent postmodern democratic and identity values reshaped the understanding of disability, placing the "normalization" of people with disabilities (PwDs) on the social agenda. On the other, following the raise of postmodern postmaterialist values, the growing affluence of postindustrial societies and the emergence of the Welfare State, tourism progressively seeped out of its historically elitist container to become a culturally legitimated goal and narrative for the working and middle classes (Oakes \& Minca, 2008). The last stage in this "cultural normalization" of tourism will be its recognition as a universal right (Gascón, 2016). The 107 signatories of the Manila Conference in 1980 recognized "the right to [...] tourism [...] as an aspect of the fulfilment of the human being" (UNWTO 1980). AT was born of the ultimate convergence between these two processes and can be officially sanctioned in 1999 by UNWTO on the Global Code of Ethics for Tourism which explicitly states that "tourism for PwDs should be encouraged and facilitated" (UNTWO, 1999). AT slowly emerged as a particular niche of the social sciences within that same fin-de-siècle zeitgeist, overlapping the disability and tourism studies (McCabe et al., 2011).

The current relevance of AT is influenced by a change of conception on disability (described on section 3), led by the social model, so that PwDs experience limitations and do not fully enjoy their travel experience, because holiday destinations and tourism companies are not fully prepared to meet their needs (Buhalis et al., 2005; Darcy \& Buhalis, 2011a). Having tourism the capacity to improve happiness and well-being, it should be a right for everyone (McCabe, 2020; McCabe \& Johnson, 2013), and, therefore PwDs' right to enjoy leisure and traveling in the same conditions as people without disabilities should be recognised (Buhalis, et al., 2012; Buhalis \& Darcy, 2011). Accessibility is also recognised as an economic profitable value for tourist companies due to the growing population of PwDs (Alén, et al., 2012; Buhalis et al., 2005; Buhalis \& Michopoulou, 2011; Domínguez, et al., 2013). Approximately, 15\% of the world population has some kind of impairment, percentage that will keep rising due to the population ageing and the increase in people suffering from chronic diseases (WHO, 2019). In addition, AT must not be understood as only benefiting the PwDs group, but also people with some kind of physical limitation as a result of accidents, surgery or pregnancy as well as the elderly (Alén, et al., 2012; Domíguez, et al., 2013; UNWTO, 2016). Thus, because accessibility can potentially improve the travel experience of a large number of people, AT is meant to become a development strategy for those tourist companies and destinations that implement it, as well as an issue public welfare programmes will increasingly have to address, as the sense of entitlement to AT raises among the population (Alén, et al., 2012; Buhalis \& Darcy, 2011; Buhalis \& Michopoulou, 2011; Domínguez, et al., 2013). Nevertheless, despite the achieved significant recognition, research in this field is still at an early stage and much remains to be done to understand and promote accessibility in all tourist destinations (Darcy \& Dickson, 2009; McKercher \& Darcy, 2018). Studying AT is therefore essential and opens the way to a broad range of research opportunities.

The purpose of this article is to offer an up-to-date original review of the academic literature on AT aimed at broadening its understanding. To this end, we investigate the evolution of topics of interest in AT and how these academic interests connect with the evolution of the theoretical foundations of AT. 
Likewise, the analysis of the literature allows us to identify the limitations of current studies, as well as future research trends and possibilities. Based on these objectives, after describing the method, we set out the most significant theoretical foundations regarding the analysis of AT (section 3). This contextualization is crucial to understand the influence played by the historical context in the way AT studies were developed. We then overview the emergence (seminal publications) and consolidation of studies on AT (section 4), describe the state of the art on AT, highlighting the themes addressed over yearly periods and the main results (section 5) and discuss the limitations of these studies and opportunities of research in AT (section 6).

\section{Methodology}

In order to broaden the understanding of scientific production in AT we have considered that the most appropriate method is the "qualitative systematic review" (Grant \& Booth, 2009). This methodology has been in great part developed by researchers from the Health Sciences field. The reason for using a study coming from the Health Sciences, such as the one by Grant \& Booth, as an illustration and reference for our own research is that, due to its very nature, this field has particularly high standards of accuracy and, therefore, authors like the cited ones have been very keen in developing systematic approaches for conducting reviews in response to increasing calls for evidence-based practice. Qualitative systematic review method is applied in other social sciences fields (Finfgeld-Connett, 2014), being the Grant \& Booth's typology acknowledged by literature reviews on tourism (Cohen \& Cohen, 2019; PahlevanSharif, et al., 2019).

Qualitative systematic review is a method for integrating or comparing findings from qualitative studies (Grant \& Booth, 2009). The purpose of this method is not aggregative in the sense of "adding studies together" as with meta-analysis, but, rather, interpretative, as it intends to broaden the understanding of a particular phenomenon. It looks for 'themes' or 'constructs' that lie in or across individual qualitative studies. This method was selected because most published studies on AT are qualitative, and also because of the multidimensional and complex nature of the phenomenon. In addition, this method allows some flexibility in literature search strategies, allowing both an exhaustive search strategy to find as many relevant qualitative research studies as possible, and a more selective search strategy geared towards a holistic interpretation of a phenomenon. Differing from a "run-of the-mill" review, the term "systematic" refers to a research protocol that "helps protect objectivity by providing explicit descriptions of the steps taken" (Tranfield et al., 2003, p. 215), including the specific questions, the focus of the study, the research strategy and the inclusion and exclusion criteria used for the reviews (Davies \& Crombie, 1998). In particular, Pahlevan-Sharif, et al. (2019: 158-159) point out that "the fundamental characteristic that differentiates systematic reviews from other types of reviews concerns the methodical procedures involved in the synthesis of findings, which provide unbiased searches with a higher degree of efficiency and quality (Liberati et al., 2009; Mulrow, 1994)". The combination of both search strategies has been fundamental for achieving the objectives of this review.

We started by making a selection of scientific articles on AT published in English and in internationally reputed academic journals related to tourism. The selection process was performed as follows:

$\checkmark$ We conducted a search by topic on the Web of Science (WoS) (a search that retrieves search terms in titles, summaries and keywords), using the keywords "accessible tourism", "touris* AND disab*", "inclus* AND tourism*". The results showed, though, that these Boolean searches have some shortcomings as they included irrelevant findings (papers whose objective was not really to analyse topics related to AT) that required additional screening. 
$\checkmark \quad$ The search within this database was complemented by another one conducted in Google Scholar (a search engine specialised in retrieving scientific documents and identifying their citations), in order to identify other articles on AT than are not included in the WoS.

$\checkmark$ To identify and track the theoretical foundations of the AT, we conducted a first analysis of the articles aimed at identifying in their references some works (other articles but, mainly, books, reports and doctoral dissertations) that have influenced the AT field. This led us to include in the review reports from official international bodies such as the UNWTO or the EU, as well as references to articles that initially gave rise to knowledge of the subject. For this purpose, we take a more selective search approach (purpose-selection).

The search produced 73 specific works on AT plus other 27 which were considered important contributions to the theoretical foundations of AT. Then, in order to analyse the bibliography in depth, a comparative method was implemented and information was organized in tables in accordance with the objectives of this study. Firstly, main themes and trends within AT were identified and classified. Secondly, within each theme, the works were analysed and shared aspects and differences among the publications were identified. Thirdly, a chronological analysis of the themes allowed us to identify a number of trends and classify the evolution of AT in the following periods: "before 2007" (17 publications), "from 2007 to 2009" (7 articles), "from 2010 to 2012" (19 publications), "from 2013 to 2015" (13 publications), and "from 2016 to 2019" (17 publications). Fourthly, we also analysed the theoretical foundations of AT and how paradigm shifts on both the concept of disability and tourism have affected the development of studies in the field. Although the effect the development of the social model of disability has had on the concept of accessibility is widely recognized, it remains to be seen whether its most advanced and multidimensional version (WHO's biopsychosocial model) is also having - or will have at some point in the future - some effect on AT studies. Finally, we analysed the main research limitations and gaps found in the studies, which subsequently allowed us to identify and suggest possible solutions to those limitations as well as possibilities and proposals for future lines of research and the practical application of AT.

The diagram below summarises the structure and analytical process of trends, results and limitations developed in the present article:

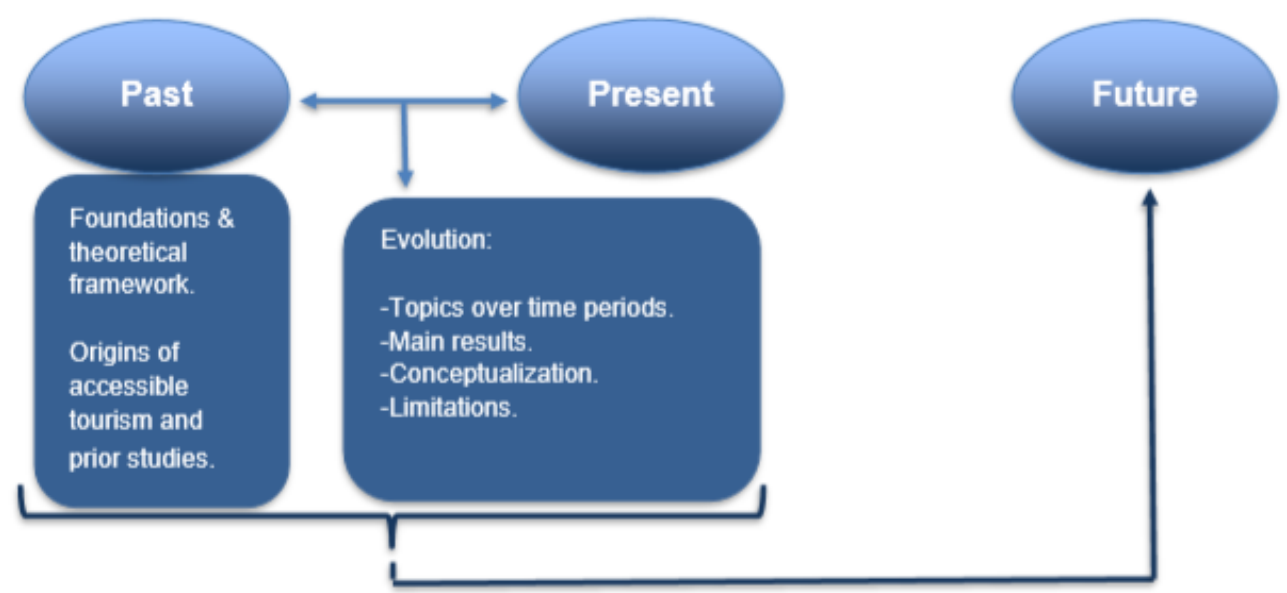

Figure 1. Analysis process of AT studies' evolution: from past to future. 


\section{The theoretical foundations of AT: The Medical, Social models and Biopsychosocial models}

Throughout history, the Medical Model of disability has prevailed in disability studies (Barnes \& Mercer, 2010; Darcy \& Buhalis, 2011a; Swain et al., 2013). According to this model, the problems faced by PwDs stem from the individual limitations imposed by their own physical disabilities, considered as personal misfortunes (the construction of disability as a "personal tragedy" as Michael Oliver first put it in his 1990 seminal work) and, therefore, concluding that the only remedy to them was medical intervention (Aitchison, 2009; Oliver 1990; Barnes \& Mercer, 2010).

The prevalence of this model started to be questioned with the publication of Stigma: The Experience of Disability in 1966 by Paul Hunt, which for the first time introduced the Social Model of disability, a theoretical framework which approached disability as a problem not exclusively lying in the individuals but also in their interaction with non-disabled people and the built environment.

The rise of disability rights movements in the 1970s was key to the development of a conceptual change (Abberey, 1987). Consequently, the Union of the Physically Impaired Against Segregation -UPIAS(1975) distinguished impairment as the "lacking part of or all of a limb, or having a defective limb, organism or mechanism of the body" and disability as "the disadvantage or restriction of activity caused by a contemporary social organization which takes no or little account of people who have physical impairments and thus excludes them from the mainstream of social activities" (UPIAS, 1975:3-4).

In an attempt to reflect the social model in the conceptualization of disability, the WHO published the International Classification of Impairments, Disabilities and Handicaps (ICIDH) in 1980, distinguishing disability -defined in a more neutral way than UPIAS has done as "any restriction or lack (resulting from an impairment) of ability to perform an activity in the manner or within the range considered normal for a human being"- from the concept of handicap, loading on it the social consequences, as "a disadvantage for a given individual, resulting from an impairment or a disability, that limits or prevents the fulfilment of a role that is normal for that individual" (WHO, 1980:28).

The development of the Social Model must be seen as reflecting and reinforcing the epochal changes of the time, characterised by the raise of the postmodern science and worldview. In the light of postmodern epistemology and ethics, PwDs became to be seen as another identity category oppressed by the hegemonic culture and institutions (Mitchell \& Synder 1997). PwDs came to be considered, in a certain way, as another kind of marginalized ethnicity, as a "political minority" partially denied of "subjectivity or agency" (Thomson, 1997). Poststructuralist critical theory influenced the Social model using its deconstruction techniques to expose the hegemonic medical discourse pervading all social PwDs structures (Petersen \& Bunton, 1997; Stoddart, 2007; Waitzkin,1989) and placing, on the other, the life experiences of PwDs at the heart of the approach, seeking alternative solutions out of the medical realm, through the creation of an enabling environment (Barnes, 2013). The adoption of the Social Model implied that, no matter the individual's impairment, none had necessarily to be excluded from most of the daily life activities provided that society gained awareness of the issue and adopted the necessary measures to remove environmental, attitude or communication barriers (Barnes \& Mercer, 2010; Darcy \& Buhalis, 2011 b; Oliver, 2013; Swain et al., 2013). When the model was applied to the field of tourism, it was argued that PwDs faced travel limitations not so much because of their physical condition itself, but because holiday destinations failed to take their needs into account (Buhalis et al., 2005; Darcy \& Buhalis, 2011a).

The Social Model gained institutional, social and academic credibility in the subsequent decade (Barnes, 2013; Oliver, 2013; Shakespeare \& Watson, 1997). However, it was also subject to intense revision by a 
string of critical literature (Badley, 1987; Bury, 1987; Hutchison, 1995; Oliver, 1990; Pfeiffer, 1993). Some of the main attacks were directed against the abuse of the socially constructed dimension of disability by certain currents, particularly those led by PwDs activists which wanted to explain disability as a form of "oppression by a society that is obsessed with normality" (Hutchison, 1995: 91)2. Others charged against WHO's ICIDH, criticizing the alleged neutrality of the disability concept and exposing the excessive "normalizing" stance still present in the WHO's definitions. The common idea in all these critiques was that there cannot be a neutral, universal, definition of what normality (or disability, for that matter) is, whether in function, performance or social role. Eventually, WHO would acknowledge the problem. It tried to make some amendments to the ICIDH in its 1993's revised edition but it would take WHO some more years to definitely substitute the 1970's classification for a new integrated multidimensional model (they would label it biopsychosocial): the International Classification of Functioning, Disability and Health (commonly known as ICF) (WHO, 2001; 2002; 2019). The ICF was a paradigm shift. Previously, disability began where health ended; once a person was disabled, it was put in a separate category. The ICF acknowledged that every human being can experience at a certain point a decrement in functionality and thereby experience some disability (WHO, 2002). In doing so, WHO institutionally 'mainstreamed' the experience of disability and recognised it as a universal human experience.

In order to do that, ICF disposed of the concept of handicap, turning back to a more complex classification that gathered all the multiple dimensions of the phenomenon around a pair of umbrella macro-concepts: On the one hand the concept of functioning, referring to "all body functions, activities and participation" (WHO, 2002: 10), on the other that of disability: an overarching term for "impairments, activity limitations and participation restrictions" (WHO, 2002:10). The ICF presents itself as an attempt to reconcile and unify the Medical and Social models: although both partially valid, neither model, on their own, is adequate. The stress is put on functioning, rather than on disability, and, instead of seen both concepts through a binary lens, they are regarded as a continuum of possible degrees and forms of functionality/disability which are the result of interactions occurring between specific biological conditions and two kinds of contextual factors: external/environmental (social attitudes, architectural characteristics, legal and social structures, as well as the climate or the terrain); and internal/personal (gender, age, coping styles, social background, education, profession, past and current experience, overall behaviour pattern or character) (WHO, 2002). Thus, biological impairment results in an enormous diversity of social dimensions of disability.

The conceptualization of disability as a multidimensional phenomenon led in the following years to the construction of a complex typology of conditions of individual impairment by scholars who started to explore the application of the concept to the tourist experience (Darcy \& Buhalis, 2011a). This approach was essential to understand the variety of accessibility needs, and provided a theoretical basis to create environments conducive to the inclusion of different kinds of PwDs. The application of multidimensional models of disability allowed to classify impairments according to their corresponding restrictions (Buhalis et al., 2005), i.e.: physical, sensory, communicative, intellectual/mental and hidden (e.g. as a result of diabetes). The novelty of this classification lay in the introduction of other individual, social, cultural, political and identity factors to build an in-depth understanding of disabling conditions (Altman, 2001; Buhalis et al., 2005; Darcy \& Buhalis, 2011a).

\section{Emergence and consolidation of AT studies}

The first academic author to use the term "accessibility" in tourism was Ralph Smith in 1987 in his publication "Leisure of disabled tourists: barriers to participation". The main objective of this article being the establishing of hypotheses and questions for future research, it was not supported by a 
collection of primary or secondary data. The article suggested that PwDs experienced barriers to participation in leisure that undermined their sense of freedom and feelings of personal control. The barriers were categorised as: intrinsic (resulting from the individuals' own levels of cognitive, physical and psychological functions); environmental (limitations imposed from the outside); and interactive, stemming from the reciprocal interactions between tourists and the environment (Smith, 1987). The article began to talk about "access" or "accessibility", although the removal of barriers in tourism had not yet been conceptualised using the AT label. The importance of this article was that it guided future research on the subject.

The Table 1 presented as follows summarises the AT themes addressed from the publication of Smith (1987) to the works made in $2005 / 2006$, being the studies published during this period considered as "initial" after the whole analysis.

Table 1. Specific themes in initial AT studies.

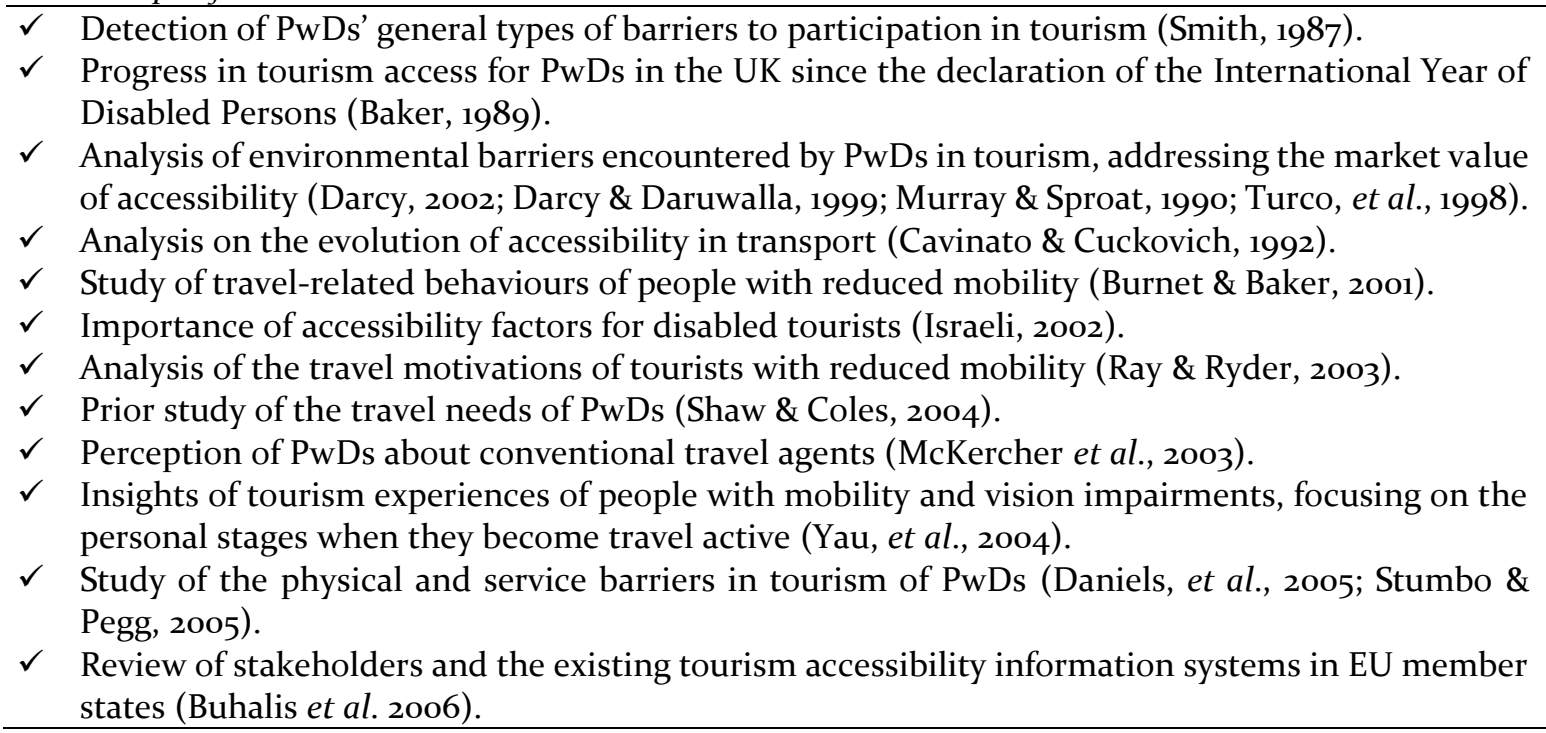

The term AT was introduced for the first time in the academic literature in 1989, in a report published by the English Tourism Council entitled "Tourism for all" (Baker, 1989). The document intended to describe the progress made in the country since 1981 (which was declared International Year of Disabled Persons) in the design, promotion and implementation of tourist services that could be enjoyed by all, regardless of age or degree of impairment.

The first academic works based on fieldwork emerged throughout the 1990s. All these studies reflected the influence of the Social Model and show a broad consensus on blaming environmental barriers as the main conditioning factor of the PwDs tourist experience. They addressed the issue of AT's market value and described the different types of barriers encountered by PwDs (Cavinato \& Cuckovich, 1992; Darcy, 2002; Darcy \& Daruwalla, 1999; Murray \& Sproat, 1990; Turco, et al., 1998), with special attention to the evolution of accessibility in transport (Cavinato \& Cuckovich, 1992).

However, the academic significance of AT studies has only gained momentum from the year 2000 onwards when high-impact journals such as Tourism Management and Annals of Tourism Research started including articles on this topic. At the beginning these works were fundamentally of an 
exploratory nature: many researchers used qualitative techniques (Daniels, et al., 2005; McKercher et al., 2003; Ray \& Ryder, 2003; Yau, et al., 2004) while those who opted for quantitative instruments limited themselves to conduct pilot surveys (Burnet \& Baker, 2001; Ray \& Ryder, 2003; Shaw \& Coles, 2004). As for the objectives pursued, the studies: a) assessed the behaviours of tourists with reduced mobility (Burnet \& Baker, 2001); b) analysed their needs and motivations (Ray \& Ryder, 2003; Shaw \& Coles, 2004); c) the processes of tourist experiences (Yau, et al., 2004); d) the barriers found in tourism (Daniels, et al., 2005; Stumbo \& Pegg, 2005); e) their perceptions of travel agents (McKercher et al., 2003); f) and the importance they attached to accessibility factors (Israeli, 2002). In short, the works focused mainly on tourists' perspectives and their knowledge as consumers. The main results indicated that disability is related to environmental criteria, to the degree of accessibility and the type of activities, highlighting the existence of a segmentation in the tourist practices and experiences according to the degree of the impairment, with people with greater levels of impairment having a very distinctive and differentiated tourist pattern (Burnet \& Baker, 2001). PwDs stated as their main motivations for embarking in the practice of tourism the need for some kind of outdoor activity and/or sport (Ray \& Ryder, 2003), the quest for new experiences, relaxation, a break from daily routine and the search for a sense of freedom (Shaw \& Coles, 2004). Daniels et al. (2005) added that the activities carried out during the holiday trip and the problems stemming from having to deal with tourism professionals were somehow similar for the PwDs and the persons without disabilities, the biggest differences lying in the latter reporting accessibility problems regarding accommodation and transport, and a lack of services adapted to their needs. The reported problems seem to be related to the poor financial capacity of PwDs (on average), as the lack of real equality in the accessing to the work market constrains many of them to take budget holiday packages which usually come with low-quality venues and services (Shaw \& Coles, 2004). For this reason, PwDs are cautious when planning their holidays, previously gathering information and reviews online and by word of mouth (Ray \& Ryder, 2003). They are sceptical about traditional travel agents, considering they do not properly meet their needs (McKercher et al., 2003; Ray \& Ryder, 2003).

Another result of the studies focusing on tourists' perspectives points to the consequences of trips on the daily life of PwDs. Travelling has positive psychological effects on them when experiences are positive, but, on the contrary, negative experiences can lower their self-esteem and confidence and lead to the decision of not travelling again (Yau, et al., 2004). In spite of all the risks and hurdles, and precisely for that reason, tourism is seen by PwDs as a metaphor for recovery. The complexity of being a tourist with an impairment involves a great amount of personal initiative, an accurate assessment of one's own capabilities, the ability to collect reliable information, and a varied array of complex skills necessary to manage the different problems/contexts/situations any trip entails (navigation and social communication skills, financial administration of the daily ordinary and extraordinary trip expenses, etc.). Travelling is a complex multidimensional task through which PwDs demonstrate to others that they can fend for themselves and regain control of their lives and their future (Yau, et al., 2004).

The ENAT (European Networkfor Accessible Tourism), a non-profit association, was established in 2006. It comprises an array of stakeholders involved in AT and has made a significant contribution to studies on the subject. Shortly after it was set up, the ENAT released the OSSATE Report with the aim of providing a review of the existing tourism accessibility information systems in EU member states. The report was essentially an inventory of accessibility schemes and data sets within the EU tourism sector (Buhalis et al. 2006) and strongly contributed to the development of the EU-funded pan-European accessibility information service for the tourism sector (ENAT, 2019). Our literature review has identified a considerable increase in the range of themes examined in AT starting in the immediate aftermath of the OSSATE report publication, possibly sparked and inspired by it. Remarkedly, the last 
15 years have seen a major increase of in-depth studies on: a) the experiences of tourists with disabilities; b) the use of new ICTs (Information and Communication Technologies) such as the Internet and social media in AT -following the path already opened by Pühretmair (2004) and Buhalis et al. (2006); market knowledge; c) the perspective of tourism managers; and d) prospective analysis of AT. The characteristics of this latter prolific period which runs to this day will be discussed in detail in the following section.

\section{State of the art on AT (2007-2019)}

Overview

The collective books "Accessible tourism: Concepts and issues" (Buhalis \& Darcy, 2011) and "Best practices in accessible tourism: Inclusion, disability, ageing population and tourism" (Buhalis et al., 2012) are worth singling out as the most relevant of this period. Both have become major reference works in the field, being cited in most of the subsequent articles about AT. They gathered and divulged the then existing body of knowledge on the matter, covering a wide array of different themes related to AT. They can be considered as useful handbooks which bring together key theoretical concepts and best practices on AT implementation.

As far as research papers in indexed journals are concerned this section provides a time period analysis on the different topics covered in these publications and the most significant results. Table 2 summarises the different topics based on yearly periods.

We observe that the themes related to AT studies become more varied from 2007 onwards, although it is from 2010 when more publications on the subject begin to emerge. The results of these works are presented below, but instead of organising them per year, as in the table, they are grouped by topic: experiences and motivations of tourists with disabilities; technological accessibility needs in tourism; studies focusing on market strategies; attitudes of tourism industry on AT; AT foresight.

In addition to identifying the topics investigated in AT, after analysing all these publications, we were able to conclude that, over time, the weight of exploratory studies declines while that of specialised works increases, studies implementing experimental methodologies are more frequent and theoretical approaches originating in other disciplines are applied to AT (for example, destination competitiveness theories or the concepts of value co-creation and learned helplessness). At the same time that there is more specialization, the studies reflect the influence of the more complex multidimensional models of disability which were already gaining momentum. Topics such as the information needs of PwDs, and the use of new technologies and social media in AT are also emergent research subfields. Tourist experience studies focus on more specific groups (visually impaired persons, caregivers...) or specific situations (flight, accommodation...). The perspective of more social actors is also taken into consideration: hotel managers, tourists without disabilities, travel agents or others. These research findings and the works in which they are reflected are developed are detailed in the following sections.

\section{Experiences and motivations of tourists with disabilities}

Whereas AT studies are still significantly influenced by the Social Model of Disability as they focus on the social dimension of tourist activities, many others also introduce multidimensional perspectives (more akin to the more recent Biopsychosocial Model -WHO, 2001-), in particular when PwDs' participation in tourism is considered to be influenced both by factors stemming from the individual itself (physical or psychological) and from the social and physical environment. The latter model has exerted a bigger influence in the most recent studies on AT. 
Table 2. Specific themes in AT studies from 2007 to 2019.

2007-2009

Attitudinal barriers encountered by tourists with physical disabilities in the Chinese tourism sector ( $\mathrm{Bi}$, et al., 2007).

$\checkmark \quad$ Issues and factors related to participation in tourism as perceived by PwDs (Packer, et al., 2007).

$\checkmark$ Accessibility schemes and their potential to meet the information needs of tourists with disabilities (Eichhorn et al., 2008).

$\checkmark$ Usability of various websites operated by hospitality and tourism companies for persons with visual impairments (Mills, et al., 2008)

$\checkmark$ The tourism experience of the blind starts to be studied as a specific subfield of AT (Packer et al, 2008)

2010-2012 $\checkmark \checkmark$ Further studies on tourism and blind people (Richards, et al., 2010; Small, 2015; Small, et al., 2012).

$\checkmark$ Criteria for selecting accommodation and PwDs' information preferences (Darcy, 2010).

$\checkmark \quad$ Web design and AT (Pühretmair \& Nussbaum, 2011)

$\checkmark$ AT in relation to financial, environmental and social sustainability (Darcy, et al., 2010; Darcy \& Dickson, 2009).

$\checkmark \quad$ Flight experiences of PwDs (Poria, et al., 2010).

$\checkmark$ Relationship between disability, physical illness and individual attitudes and the degree and modes of participation in tourism (Lee, et al., 2012; Pagán, 2012; Tsai, 2010).

$\checkmark$ Perception and attitudes of the service sector towards PwDs (Bizjak, et al.,2011; Darcy \& Pegg, 2011; Patterson, et al., 2012).

$\checkmark \quad$ In-depth analysis of further aspects of PwDs tourist experiences, such as the role of associations, personal implications, or new barriers found (Blichfeldt \& Nicolaisen, 2011; Poria et al.,2011), and motivations to travel (Blichfeldt \& Nicolaisen, 2011; Shi, et al., 2012).

$\checkmark$ New technologies as a market tool for tourism enterprises (Buhalis \& Michopoulou, 2011).

$\checkmark$ Economic potential of the tourism services for the elderly as a particular form of AT (Alén, et al., 2012; Domínguez, et al., 2013).

2013-2015 $\checkmark$ Tourism of deaf people starts to be studied as a specific subfield (Zajadacz, 2014).

$\checkmark$ PwDs' resistance strategies during the trip (Eichhorn, et al., 2013).

$\checkmark$ Requirements and implications of AT information systems (Michopoulou \& Buhalis, 2013).

$\checkmark$ Co-creation of value between hotel managers and their customers with disabilities (Navarro, et al., 2014).

$\checkmark$ Prospective analysis on the future of AT (Cruces, 2015; Gillovic \& McIntosh, 2015; Michopoulou et al., 2015).

$\checkmark$ Effect of tourism to the self-realization, psychological well-being and social integration of PwDs (Kastenholz, et al.,2015; Pagan, 2015).

$\checkmark$ Macro interregional comparative analysis AT destinations competitiveness factors (Spain-Australia) (Vila, et al., 2015).

2016-2019 $\checkmark \quad$ PwDs' perceptions on tourism social media (Altinay et al., 2016).

$\checkmark$ Formulas to encourage tourist accommodation establishments to implement accessibility (Capitaine, 2016). 


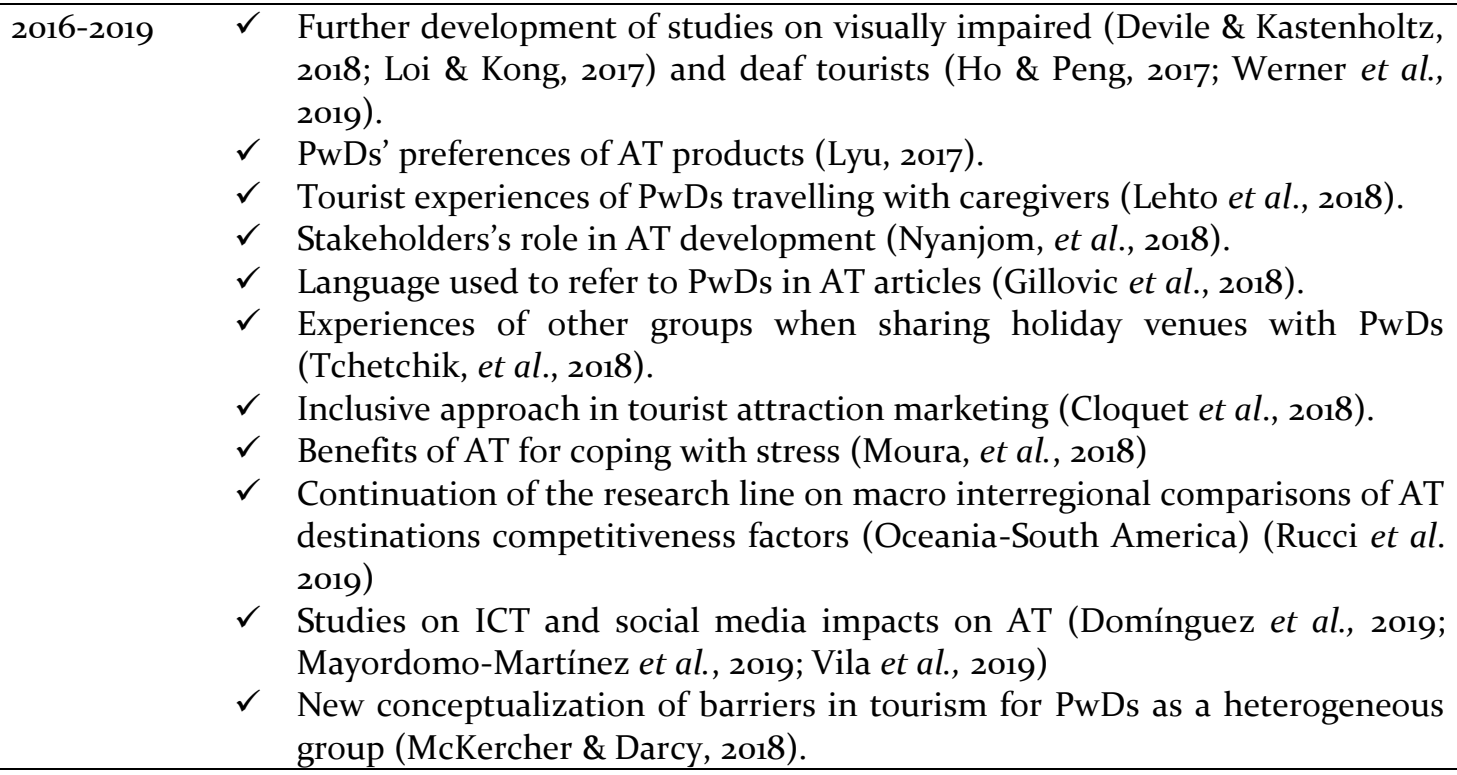
2018; Loi \& Kong, 2017) and deaf tourists (Ho \& Peng, 2017; Werner et al., 2019).

$\checkmark \quad$ PwDs' preferences of AT products (Lyu, 2017).

$\checkmark$ Tourist experiences of PwDs travelling with caregivers (Lehto et al., 2018).

$\checkmark \quad$ Stakeholders's role in AT development (Nyanjom, et al., 2018).

$\checkmark \quad$ Language used to refer to PwDs in AT articles (Gillovic et al., 2018).

$\checkmark$ Experiences of other groups when sharing holiday venues with PwDs (Tchetchik, et al., 2018).

$\checkmark \quad$ Inclusive approach in tourist attraction marketing (Cloquet et al., 2018).

$\checkmark$ Benefits of AT for coping with stress (Moura, et al., 2018)

$\checkmark$ Continuation of the research line on macro interregional comparisons of AT destinations competitiveness factors (Oceania-South America) (Rucci et al. 2019)

$\checkmark \quad$ Studies on ICT and social media impacts on AT (Domínguez et al., 2019; Mayordomo-Martínez et al., 2019; Vila et al., 2019)

$\checkmark$ New conceptualization of barriers in tourism for PwDs as a heterogeneous group (McKercher \& Darcy, 2018).

Source: elaborated by the authors

As an illustration of this influence, Lee, et al., (2012) consider that barriers themselves do not stop PwDs from participating in tourism, but, instead, 'learned helplessness' does. Lee et al.'s study sees the three kinds of tourist barriers identified by Smith (1987) as having a combined negative impact on "learned helplessness" and therefore on the intention to travel. Pagan (2012) and Tsai (2010) attribute travel participation to a combination of psychological and physical causes, affirming that the perception of one's own health affects the willingness to go on a holiday trip and the specific modes of travelling: the less the individual sees himself as an impaired person the more enthusiastic about taking part in some kind of tourism activity, emphasizing that tourism industry should consider these aspects in order to become more inclusive. Devile \& Kastenholtz (2018) draw a list of motivating strategies through which tourists affected by blindness overcome the deterrent effect of travel constraints. These strategies involve the interplay of a set of factors both at the individual level (an optimistic personality, previous travel experience, determination/resilience, curiosity, self-confidence or acceptance of disability), the interpersonal (encouragement and support from relatives, friends, community and travel companions, tourism staff awareness), and the structural ones (i.e. factors associated with accessible information or adequate services and attractions that meet the needs of PwDs).

The search for independence, adventure and risk constitute a related set of specific drivers or motivating factors for PwDs to engage in a tourist experience (Shi, et al., 2012). Blichfeldt \& Nicolaisen (2011) add as PwDs' main motivation the desire to be temporarily freed from their role as "objects of care". In addition, tourism have positive effects in social integration (Kastenholz, et al., 2015), stress-coping (Moura et al., 2018), enhancing of self-satisfaction (Pagan, 2015), and represents an opportunity for selfaffirmation and self-identity (Eichhorn, et al., 2013).

Poria, et al. (2010) study the flying experience of PwDs after detecting this is the most problematic mode of transport for them. Some of the issues most recurrently reported by the informants PwDs are feeling humiliated by security and boarding procedures and purposely dehydrating themselves to avoid having to go to the toilet during the flight. 
PwDs usually travel with members of an association rather than with other groups (Bi, et al., 2007). These associations have been reported to provide relevant information and act as forums in which PwDs get to learn from each other's experiences (Blichfeldt \& Nicolaisen, 2011). They act as specialised travel agencies organising holiday packages, enabling the acquisition of "tourist" roles by PwDs (Blichfeldt \& Nicolaisen, 2011). Some studies, though, have revealed a significant amount of rejection among PwDs towards this kind of customised trips, as informants state that they wish to see themselves as ordinary people without placing disability at the centre of their identity (Eichhorn, et al., 2013).

Over the last decade scholars have turned towards specifically studying the experiences of blind (Devile \& Kastenholtz, 2018; Loi \& Kong, 2017; Mills, et al, 2008; Richards, et al., 2010; Small, 2015; Small, et al., 2012) and deaf (Zajadacz, 2014; Zajadacz; Werner et al., 2019) tourists, as well as those who travel accompanied by their caregivers (Lehto et al., 2018; Loi \& Kong, 2017; Small, 2015). Those studies focused on the experience of visually-impaired tourists' reported experiences and barriers typically associated with this type of impairment: they must travel with their guide dogs, they need to build a sensory and space understanding (Loi \& Kong, 2017; Richards, et al., 2010; Small, et al., 2012), and require tactile, aromatic, sound and movement experiences (Loi \& Kong, 2017; Small, et al., 2012). Sometimes travelling with non-blind friends or relatives helps them not to lose their sense of direction and to get a better understanding of their surroundings but, at the same time, it can also undermine their feeling of personal autonomy, as they perceive themselves conditioned by and dependent of their companions (Loi \& Kong, 2017; Small, 2015).

Technological accessibility needs in tourism

The role of technological accessibility in tourism focuses mainly on the impact of ICTs, with a particular interest on uses of the Internet and smartphone applications, following a global trend in which new technologies are playing an ever-greater role in the tourism industry.

Technological accessibility in tourism is a broad concept interrelated with information and online accessibility (Buhalis \& Michopoulou, 2006, 2011). In these areas, a general consensus exists that information available on the Internet relating to tourism infrastructures and services should be highly detailed and presented in formats that can be understood by people with visual, hearing and intellectual disabilities (Buhalis \& Michopoulou, 2006, 2011; Darcy, 2010; Eichhorn \& Buhalis, 2011; Eichhorn et al., 2008; Mayordomo-Martínez et al., 2019; Michopoulou \& Buhalis, 2013). Regarding environmental accessibility, not all PwDs have the same limitations, so they need the right kind of information adapted to their specific needs (Darcy, 2010; Eichhorn et al., 2008; Michopoulou \& Buhalis, 2013). The preferred information formats are a combination of text, floorplans and photography, that include sizes, descriptions of spaces and of adaptations (Darcy, 2010; Michopoulou \& Buhalis, 2013).

A significant number of studies show that most web pages only display very generic information and cannot always support a variety of assistive technologies (Michopoulou \& Buhalis, 2013; Pühretmair \& Nussbaum, 2011). According to Michopoulou \& Buhalis (2013), the main challenges for building an AT information system are: interoperability, content integration, personalisation and accessible design. This means that information systems should at least facilitate the early filtering of the minimal features required from the built environment for each type and degree of impairment, in order to allow customers to conduct their own assessment, take their own decisions and make their own choices. The systems should also include information about the geographical/urban environment as a whole: not only describing in detail the accessible venues in the destination but also the accessible routes to get to them, through some kind of virtual accessibility maps (Michopoulou \& Buhalis, 2013). The last trends show a very new promising ramification of the ICTs theme. 
As for the role played by social media, this has been scarcely studied in the field of AT. The few works that have addressed this issue have found that social media are also important when searching for information, since PwDs use them to expand their knowledge of accessible places and venues (Altinay et al., 2016). Social media allows the sharing of knowledge and experiences and are also useful to raise awareness about the need for accessibility (Altinay et al., 2016). Altinay et al. (2016) concluded in their study that integrating technology to the tourist experience makes life easier, especially for disabled people.

The research subfield on ICTs applied to AT still remains mainly influenced by the social perspective of disability, which means there may exist innumerable research avenues to be explored.

\section{Studies focusing on market strategies}

In the late years, we can find more specialized research oriented towards market segmentation and its links to PwDs' market requirements and customer preferences, as well as identifying factors of competitiveness within and across countries.

PwDs must be considered as a non-homogeneous market with different sub-segments (Buhalis \& Michopoulou, 2011; Figueiredo, et al., 2012), as a result of new ways of understanding disability. Therefore, PwDs require tourist services adapted to particular needs (Buhalis \& Michopoulou, 2011; Darcy, 2010). Buhalis and Michopoulou (2011) argue that the market should be understood based on types as well as degrees of impairment/accessibility requirements. This heterogeneity entails both challenges and opportunities for the tourism industry.

PwDs' specific priorities have been detected through the conducting of surveys. According to some of the results, the dimensions of disability have a big influence on the hierarchy of preferences expressed by PwDs (Darcy, 2010), the factor with the biggest weight in tourist customer satisfaction being accommodation accessibility (Darcy, 2010; Lyu, 2017). This, altogether with accessible conditions in tour buses, are features for which PwDs would be willing to pay more (Lyu, 2017).

Other researchers have examined AT destinations from the point of view of the competitiveness factors. In a comparative study between Australia and Spain that used data sets, Vila, et al. (2015) concluded that intrinsic tourist attractions, such as the climate, locale and tourist structure, played a bigger role in Spain's competitiveness as a destination for PwDs whereas quality of services, brand and infrastructure had more weight in the case of Australia. Both countries, with their individual number of clusters, follow similar patterns, suggesting that the concept of an accessible tourism market was validated through this two-country study. It was also found that the large capital cities in both countries, also considered as big tourist destinations, provided greater accessibility in their tourist offer.

\section{Attitudes of the tourism industry on AT}

Some studies on AT have focused on understanding the viewpoint of tourism entrepreneurs (Capitaine, 2016; Darcy \& Pegg, 2011; Gillovic \& McIntosh, 2015; Navarro et al., 2014; Nyanjom, et al.,2018; Patterson et al., 2012): they examined their perceptions and attitudes towards disability and accessibility, conducted cost-benefit analyses of AT, and tried to understand their motivations or reluctances to implementing it. Some of the results showed that entrepreneurs are generally keen on improving the quality of service and experience of PwDs as they would do with any other type of customer (Darcy \& Pegg, 2011). However, research by Patterson et al. (2012) on the experiences and attitudes of Australian tourism companies pointed out that the hotel entrepreneurs' main motivations in implementing accessibility are merely to comply with existing legislation. Tour operators' demands contribute to this 
as they pressure their suppliers into turning their products and services accessible to PwDs (Patterson et al., 2012). Other works have identified a similar lack of motivation to improve PwDs' tourist experience beyond the legal requirements. A study conducted by Navarro et al. (2014) on the co-creation of value between hotel entrepreneurs and guests with disabilities in a Mediterranean destination, found that the former are more oriented towards the general public than to the PwDs segment and recognise that their venues are barely adapted to PwDs' needs. Hotel managers get to know about PwDs' demands and claims through the complaints and suggestions the guests make to hotel staff. However, PwDs believe their comments are not seriously taken into account and that generally, the hotel management will not make any actual changes for the sake of future customers (Gillovic \& McIntosh, 2015; Navarro et al., 2014).

Hoteliers say that accessibility presents many advantages in the case of conference tourism and PwDs groups (Capitaine, 2016; Patterson, et al., 2012). However, despite the advances, studies show that few of them regard accessibility as a market opportunity (Capitaine, 2016; Darcy \& Pegg, 2011; Patterson, et al., 2012) and collaboration between the different sub-sectors of the industry in order to promote AT is minimal (Nyanjom, et al.,2018). Patterson et al. (2012) found that the main reason lies in the low levels of hotel occupancy and use of accessible products and services by PwDs, that is, in the small size of this niche market. Capitaine (2016), in turn, concluded that there were misconceptions among hotel entrepreneurs regarding disability and accessibility. For example, some believed that being close to a hospital is essential for accessibility or that PwDs easily adapt to inaccessible premises.

Overall, it may be said that more research is needed to understand the reluctance of the tourist industry towards AT, as a settled literature that enhances the potential economic benefits of AT still collides with a negative attitude of many entrepreneurs.

\section{Foresight in AT}

The future of AT is another subject that has gained relevance in recent years. Foresight analyses have been conducted through consultations to experts (Darcy, et al., 2010; Gillovic \& McIntosh, 2015; Michopoulou et al., 2015) and based on a scenario planning framework (Cruces, 2015).

Implementing AT requires a process of social change, and continuous collaboration between all stakeholders (architects, companies, state administrations, PwDs, etc.) (Gillovic \& McIntosh, 2015; Michopoulou et al., 2015). This collaboration needs to be based on all actors aligned towards common goals and strategies (Michopoulou et al., 2015). Cruces (2015) affirms that in a future scenario aiming at the ideal of full accessibility, it is consensus, cooperation and empathy of all parties involved, as well as state-of-the-art technology, that will prevail.

Prospective studies reflect an interest in further exploring the relationship between AT and sustainability. Darcy et al. (2010) examined AT main dimensions as well as financial, environmental and social considerations (sustainability aspects) and concluded that AT will have to take into account the useful life and intergenerational functionality of the tourist venues, acknowledging the relationship between aging, disability and people's lifelong capacities (Darcy \& Dickson, 2009; Darcy et al., 2011; Darcy et al., 2010). The Universal Design does not simply target the accessibility standards of venues which are necessary to guarantee PwDs' basic access rights: it supports the operational management of tourist facilities, reduces operating costs, helps to achieve a greater social equality and makes tourism more sustainable in the long term (Darcy et al., 2011; Darcy, et al., 2010). 
This particular topic within AT studies is gaining momentum since the beginning of the last decade and brings us to the need to address the main objectives of this paper: to analyze where research on AT is likely to be heading in the near future.

\section{Limitations of AT studies and research trends}

The study of AT is characterized by an increasing complexity and multidimensional approach that is changing the way we understand PwDs' tourism, in a similar fashion as the Biopsychosocial model has had a transformative effect in the way disability is currently understood. Being a complex phenomenon, the research conducted so far has encountered some important hurdles that lead to significant limitations in the building of its knowledge base that need to be highlighted and explained.

The first limitation is of a methodological nature. So far, the AT subfield has only produced qualitative studies that collect data by means of small convenience sampling or snowballing techniques through direct contact with PwDs associations. This limitation is mainly due to the fact of PwDs methodologically being what the researchers call "a hard-to-reach population" (Marpsat \& Razafindratsima, 2010; Sydor, 2013). It is also difficult to conduct a street survey on PwDs, since relying on physical appearance for the sample could be considered as a biased approach: disabilities cannot necessarily be detected at first sight, indeed, most of them are invisible (Buhalis, et al., 2005; Darcy \& Buhalis, 2011 a). For this reason, most of the surveys are conducted on-line.

A survey based on a wider range of data obtained by random sampling would avoid some of the biases these studies may have incurred into (such as interviewing people belonging to rather homogenous social groups, or just people with access to ICTs). Census-based survey would also allow to make stratified sample calculations based on knowledge of the sample universe characteristics (Fowler, 2013) and make comparisons between variables such as income, age, sex, or education, that help to understand the sociological differences between the PwDs who travel and those who do not. However, these research objectives collide with the high financial cost of such studies (Fowler, 2013).

The second major limitation stems from the complexity of disability, both as a social and a physical phenomenon. As illustrated by the dimensions of disability and the ICF model, disabilities are highly diverse and involve multiple social factors. Therefore, studies should narrow down their object of study instead of always considering the whole range of factors that influence PwDs tourism. Most studies are qualitative and explore different themes and contexts. Further research must be conducted to understand the weight and influence of the different contextual factors, dimensions and/or variables in every particular type of impairment/disability. Intellectual or hidden impairments have been so far shunned by the majority of studies. This represents a huge research gap that needs to be filled in the coming years.

Likewise, after reviewing the literature on experiences and motivations of tourists with disabilities, new questions arise that evidence the need to deepen on the meanings and motivations, the complexity of factors that influence the decision-making process to undertake a tourist trip, as well as the experiences with other means of transports (besides the plane) and/or with other kinds of tourist enterprises.

It is fair to say, however, as reflected in the trend described in the present study, that an increasing number of qualitative studies are addressing new dimensions of the phenomenon and increasing the complexity of the research field. 
With regard to new technologies, it is worth noting that studies on the impact of ICTs and social media on the development of AT have mushroomed in recent years, with some innovative inroads worth mentioning: Vila et al. (2019) and Domínguez et al. (2019) have focused on studying the issue from a top-down perspective, by assessing the level of governmental commitment to promote, regulate and uphold PwDs' right to accessible on-line tourist information. Others, like Mayordomo-Martínez et al. (2019) have taken a step towards integrating theory and practice, by applying its research to the design of a smartphone app providing accessibility information for PwDs. In a similar way to what can be said of tourism experiences, the application of the Biopsychosocial Model (multidimensionality of disability) to the field of ICTs' in accessible tourism opens up to many possible new research lines to be explored in the future.

We also observed an increasing research interest to understand the underlying causes leading to international differences and similarities in factors of competitiveness between accessible destinations (Rucci et al., 2019; Vila et al., 2015), cross-checking secondary and primary data based on the stakeholders' experiences.

Regarding works on the experience of the tourism industry, future studies could delve into the reasons of the PwDs market unprofitability: is it due to the tourism enterprises not properly advertising their accessible products? A substantially high percentage of PwDs never go on holiday in spite of the existence of an accessible offer. Are there other reasons (cultural, psychological, economical) discouraging them to engage in tourism activities? Another question to explore is why stakeholders do not collaborate more intensely with one another to develop AT.

As a road map for the future of AT studies, we propose to keep working on the analyses of cultural, contextual and disability-based differences in the relationship between tourism and the well-being of PwDs, and specifically, to aim at understanding the differences between disabled individuals experiencing leisure tourism in the context of social tourism programmes and the general population, such as Moura et al. (2018) have already started to do. Likewise, further research should be conducted, following the path opened by Tchetchik et al. (2018), on the experiences of people without disabilities travelling with PwDs, in order to identify possible relations of collaboration/complementarity or conflict (that may arise as a result of incompatible goals and preferences, emotional friction etc.) We also propose - learning from Lehto et al.'s (2018) study to conduct more in-depth comparative international research into the factors affecting tourist shared experiences, differentiating by type of disability and specific nature of the relationship with travel companions. In their study on AT online resources in Scandinavian countries, Domínguez et al. (2019) affirm that the degree and modes of implementation of AT are strongly influenced by their welfare policies. This opens the door to a very promising line of research that explores the relationship between AT and public policies whether in a country-by-country or an international comparative approach.

Future researchers could also find it fruitful to follow Nyanjom et al.'s (2018) steps in order to better understand the complex process of interaction/collaboration between AT stakeholders. It is equally worth noting the emergence of a line of research (Capitaine, 2016) which inquires about the channels through which tourism professionals obtain information on AT and its PwDs customer base.

In the field of marketing, new lines of research have been opened by Tchetchik, et al. (2018) with their work on the impact of advertising campaigns that use PwDs visual themes and inclusive alternative narratives launched by some hotels, and by Lyu (2017), with a study that applies diverse segmentation strategies to understand how seasonal, behavioural and psychological factors affect variations in the 
preferences of tourists with disabilities, including the ground-breaking application of algorithms that offer practical solutions to identify sources of preference heterogeneity. This pioneering use of mathematical methodologies opens up a new research frontier. Lyu's work (2017) is also innovative in the conducting of surveys that abandon the convenience sampling in favour of more representative sample sizes and other researchers should consider following his lead.

\section{Conclusions}

We would like to wrap this paper up by highlighting its contribution to the understanding of the AT phenomenon: not only are literature reviews on the topic scant, but they also often lack the critical analysis we have undertaken Through the identification of trends in subtopics, common limitations and shortcomings and research gaps it has been possible to ask new research questions and offer valuable proposals aimed at overcoming some of the hurdles AT researchers struggle with.

The literature review has allowed us to observe how, as research on AT comes of age, the weight of exploratory studies declines while that of specialised works increases, studies implementing experimental methodologies are more frequent and theoretical approaches originating in different disciplines are applied. We have also been able to identify emergent topics which could become fullgrown lines of research in the future, such as PwDs' technological and information needs, those focusing on some specific subgroups within the PwDs' collective and those exploring AT from the point of view of tourism companies' managers, tourists without disabilities, travel agents and other stakeholders.

We have also analysed how the Biopsychosocial model has played an increasing significant role in the evolution of AT studies. The most recent studies on AT fully embrace the model, addressing accessibility by taking into account the different degrees of interaction between the individual (physical, psychological) and socio-environmental dimensions. However, it is very important to highlight that, up to this date, the published works incorporating this perspective are still scant. Consequently, future research on AT must be aimed at strengthening this approach by further studying all the possible situations resulting from the combined and interacting effect of the individual and social factors on accessibility in the context of tourism. These are challenges that, once addressed and overcome, can lead to very fruitful breakthroughs.

As far as the methodological limitations on AT research are concerned, faced with the difficulty of accessing PwDs, surveys have been conducted using qualitative sampling. This has not prevented knowledge from being generated on the subject, but it would be interesting to gain access to populations that lie out of the most common social groups where informants are usually selected from. One solution has already been offered by a methodology design that allows to broaden the sample size out of the usual convenience sampling methods. However, the researchers' efforts alone might not be enough to overcome this methodological limitation. Some sort of pressure on governments might be necessary to include the "disability" category in official tourism surveys and foster the creation of statistical observatories on disability. The collection of extensive statistical information about PwDs could be a huge leap forward towards a more profound understanding of the overt and latent influences of disability on AT.

This article can be a helping guide and a starting point for researchers trying to gain an overarching picture of the subfield or seeking for research gaps to fill with their own future work, both of them useful strategies when it comes to attempting publication in international high impact academic journals. Our paper also intends to be useful for all sorts of stakeholders involved in AT. On the one hand, the knowledge on AT provided by this paper can be a useful tool for students and professionals 
of tourism, considering the current lack of information in this field. On the other hand, overcoming research limitations and gaps in knowledge may be a proactive step, from a research-action perspective, to help combating the existing accessibility deficits in tourist destinations and to develop specialised products that increase the satisfaction of the tourist experience and improve social inclusion, not only for the PwDs' sake, but for everyone's, regardless of their physical condition.

This study also presents its own limitations. First, there may be more valuable research on AT, but they have been, but it has not been identified as it is not written in English. It would be interesting that this article becomes the starting point for the study of trends and limitations of AT studies by language and/or country, since social contexts are different in each part of the world. In addition, due to the large number of analysed works, a synthesis had to be carried out and it was not possible to collect all the nuances contained in the studies. In any case, researchers and professionals interested in AT are invited to take this paper as a reference to deeply investigate them and broaden their knowledge on the subject.

\section{Endnotes}

${ }^{1}$ Universal Design is the design and composition of an environment so that it can be accessed, understood and used to the greatest extent possible by all people regardless of their age, size, ability or disability. An environment (or any building, product, or service in that environment) should be designed to meet the needs of all people who wish to use it (Centre for Excellence in Universal Design, 2018).

${ }^{2}$ An example of this radical position can be illustrated by the following excerpt from a book published with the support of the British Council of Organizations of Disabled People: "Human knowledge technology and collective resources are already such that our physical or mental impairments need not prevent us from being able to live perfectly good lives. It is society's unwillingness to employ these means to altering itself rather than us which causes our disabilities. This is what we call the Social Model of Disability" (Rieser \&Mason, 1992: 15).

\section{References}

Abberley, P. (1987). The concept of oppression and the development of a social theory of disability. Disability, handicap \& Society, 2(1), 5-19.

Aitchison, C. (2009). Exclusive discourses: Leisure studies and disability. Leisure Studies, 28(4), 375-386.

Alén, E., Domínguez, T., \& Losada, N. (2012). New opportunities for the tourism market: Senior tourism and accessible tourism. In M, Kasimoglu (ed.) Visions for global tourism industry: Creating and sustaining competitive strategies. London: InTechOpen, 139-166.

Altinay, Z., Saner, T., Bahçelerli, N. M., \& Altinay, F. (2016). The role of social media tools: accessible tourism for disabled citizens. Journal of Educational Technology E Society, 19(1), 89.

Altman, B. M. (2001). Disability definitions, models, classification schemes, and applications. In G. L, Albrecht, K. D, Seelman \& M, Bury (ed.) Handbook of disability studies. Thousand oaks: Sage Publications, 97-122.

Badley, E. M. (1987). The ICIDH: Format, application in different settings, and distinction between disability and handicap: A critique of papers on the application of the international classification of impairments, disabilities, and handicaps. International Disability Studies, 9(3), 122-125.

Baker, M. (1989). Tourism for All: A report of the working party chaired by Mary Baker. London: English Tourist Board in association with the Holiday Care Service, the Scottish Tourist Board, the Wales Tourist Board.

Barnes, C. (2013). Understanding the social model of disability: Past, present and future. In N, Watson \& S, Vehmas (ed.) Routledge handbook of disability studies. London: Routledge, 26-43.

Barnes, C., \& Mercer, G. (2010). Exploring disability. Cambridge: Polity. 
Bi Y, Card JA \& Cole ST (2007). Accessibility and attitudinal barriers encountered by Chinese travellers with physical disabilities. International Journal of Tourism Research, 9(3), 205-216.

Bizjak B, Knežević, M \& Cvetrežnik S (2011). Attitude change towards guests with disabilities: Reflections from tourism students. Annals of Tourism Research, 38(3), 842-857.

Blichfeldt BS \& Nicolaisen J (2011). Disabled travel: not easy, but doable. Current Issues in Tourism, 14(1), 79-102.

Buhalis, D., \& Darcy, S. (Eds.). (2010). Accessible tourism: Concepts and issues. Bristol: Channel View Publications.

Buhalis, D., Darcy, S., \& Ambrose, I. (Eds.). (2012). Best practice in accessible tourism: Inclusion, disability, ageing population and tourism. Bristol: Channel View Publications.

Buhalis, D., Eichhorn, V., Michopoulou, E., \& Miller, G. (2005). Accessibility market and stakeholder analysis. University of Surrey y One Stop Shop for Accessible Tourism in Europe (OSSATE).

Buhalis, D., \& Michopoulou, E. (2011). Information-enabled tourism destination marketing: addressing the accessibility market. Current Issues in Tourism, 14(2), 145-168.

Buhalis, D., Michopoulou, E., Michailidis, S., \& Ambrose, I. (2006). An eTourism portal for the disabled tourism market in Europe: the OSSATE portal design (One-Stop-Shop for Accessible Tourism). CAUTHE 2006: To the City and Beyond, 109.

Burnett, J. J., \& Baker, H. B. (2001). Assessing the travel-related behaviors of the mobility-disabled consumer. Journal of Travel Research, 40(1), 4-11.

Bury, M. R. (1987). The ICIDH: a review of research and prospects. International disability studies, 9(3), 118-122.

Capitaine, V. (2016). Inciting tourist accommodation managers to make their establishments accessible to people with disabilities. Journal of Tourism Futures, 2(2), 196-205.

Cavinato, J. L., \& Cuckovich, M. L. (1992). Transportation and tourism for the disabled: An assessment. Transportation Journal, 31 (3), 46-53.

Cohen, S. A., \& Cohen, E. (2019). New directions in the sociology of tourism. Current Issues in Tourism, 22(2), 153-172.

Cloquet, I., Palomino, M., Shaw, G., Stephen, G., \& Taylor, T. (2018). Disability, social inclusion and the marketing of tourist attractions. Journal of Sustainable Tourism, 26(2), 221-237.

Cruces, R. (2015). Removing "invisible" barriers: opening paths towards the future of accessible tourism. Journal of Tourism Futures, 1(3), 269-284.

ENAT (2019). OSSATE Inventory of Accessible Tourism Information Schemes. ENAT. European Network for Accessible Tourism. URL: https://www.accessibletourism.org/?i=enat.en.reports.427 (Accessed on 2.8.2019)

Daniels MJ, Rodgers EBD \& Wiggins BP (2005). “Travel Tales”: an interpretive analysis of constraints and negotiations to pleasure travel as experienced by persons with physical disabilities". Tourism Management, 26(6), 919-930.

Darcy, S (2002). Marginalised participation: Physical disability, high support needs and tourism. Journal of Hospitality and Tourism Management, 9(1), 61-73.

Darcy, S (2010). Inherent complexity: Disability, accessible tourism and accommodation information preferences. Tourism Management, 31(6), 816-826.

Darcy, S., \& Buhalis, D. (2011 a). Conceptualising disability. In Buhalis, D., \& Darcy, S. (Eds.). Accessible tourism: Concepts and issues. Bristol: Chanel View Publications, vol 45, 21-44.

Darcy, S., \& Buhalis, D. (2011 b). Introduction: from disabled tourists to accessible tourism. In Buhalis, D., \& Darcy, S. (Eds.). Accessible tourism: Concepts and issues. Bristol: Chanel View Publications, vol 45, 1-20.

Darcy, S., Cameron, B., \& Pegg, S. (2010). Accessible tourism and sustainability: a discussion and case study. Journal of Sustainable Tourism, 18(4), 515-537. 
Darcy, S., \& Daruwalla, P. S. (1999). The trouble with travel: People with disabilities and tourism. Social Alternatives, 18(1), 41.

Darcy, S., \& Dickson, T. J. (2009). A whole-of-life approach to tourism: The case for accessible tourism experiences. Journal of Hospitality and Tourism Management, 16(1), 32-44.

Darcy, S., \& Pegg, S. (2011). Towards strategic intent: Perceptions of disability service provision amongst hotel accommodation managers. International Journal of Hospitality Management, 30(2), 468-476.

Davies, H. T., \& Crombie, I. K. (1998). Getting to grips with systematic reviews and metaanalyses. Hospital medicine, 59(12), 955.

Devile, E., \& Kastenholz, E. (2018). Accessible tourism experiences: the voice of people with visual disabilities. Journal of Policy Research in Tourism, Leisure and Events, 10(3), 265-285.

Domínguez, VT., Alén González, E., \& Darcy, S. (2019). Accessible tourism online resources: A Northern European perspective. Scandinavian Journal of Hospitality and Tourism, 19(2), 140-156.

Domínguez T, Fraiz JA \& Alén E (2013). Economic profitability of accessible tourism for the tourism sector in Spain. Tourism Economics, 19(6), 1385-1399.

Eichhorn, V., Miller, G., Michopoulou, E., \& Buhalis, D. (2008). Enabling access to tourism through information schemes? Annals of Tourism Research, 35(1), 189-210.

Eichhorn, V., Miller, G., \& Tribe, J. (2013). Tourism: a site of resistance strategies of individuals with a disability. Annals of Tourism Research, 43, 578-60o.

Emrouzeh, M. P., Dewar, K., Fleet, G., \& Bourgeois, Y. (2017). Implementing ICT for Tourists with Disabilities. Paper presented at the 2017 International Conference on E-Education, E-Business and E-Technology (ICEBT), September 2017, Canada.

Figueiredo, E., Eusébio, C., \& Kastenholz, E. (2012). How diverse are tourists with disabilities? A pilot study on accessible leisure tourism experiences in Portugal. International Journal of Tourism Research, 14(6), 531-550.

Finfgeld-Connett, D. (2014). Use of content analysis to conduct knowledge-building and theorygenerating qualitative systematic reviews. Qualitative Research, 14(3), 341-352.

Fowler Jr, F. J. (2013). Survey research methods. Thousand oaks: Sage publications.

Gascón, J. (2016). Deconstruyendo el derecho al turismo/Deconstructing the right to tourism. Revista CIDOB d'Afers Internacionals, 113, 51-69.

Gillovic, B., \& McIntosh, A. (2015). Stakeholder perspectives of the future of accessible tourism in New Zealand. Journal of Tourism Futures, 1(3), 223-239.

Gillovic, B., McIntosh, A., Darcy, S., \& Cockburn-Wootten, C. (2018). Enabling the language of accessible tourism. Journal of Sustainable Tourism, 26(4), 615-630.

Grant, M. J., \& Booth, A. (2009). A typology of reviews: an analysis of 14 review types and associated methodologies. Health Information \& Libraries Journal, 26(2), 91-108.

Ho, C. H., \& Peng, H. H. (2017). Travel motivation for Taiwanese hearing-impaired backpackers. Asia Pacific Journal of Tourism Research, 22(4), 449-464.

Hunt P (Ed.). (1966). Stigma: The experience of disability. London: Dublin. G. Chapman.

Hutchison, T. (1995). The classification of disability. Archives of disease in childhood, 73(2), 91.

Israeli, A. A. (2002). A preliminary investigation of the importance of site accessibility factors for disabled tourists. Journal of Travel Research, 41(1), 101-104.

Kastenholz, E., Eusébio, C., \& Figueiredo, E. (2015). Contributions of tourism to social inclusion of persons with disability. Disability $\mathcal{E}$ Society, 30(8), 1259-1281.

Lee BK, Agarwal S \& Kim HJ (2012). Influences of travel constraints on the people with disabilities' intention to travel: An application of Seligman's helplessness theory. Tourism Management, 33(3), 569-579.

Lehto, X., Luo, W., Miao, L., \& Ghiselli, R. F. (2018). Shared tourism experience of individuals with disabilities and their caregivers. Journal of destination marketing E management, 8, 185-193. 
Liberati, A., Altman, D. G., Tetzlaff, J., Mulrow, C., Gøtzsche, P. C., Ioannidis, J. P., Clarke, M., Devereaux, P.J., Keijnen, J. \& Moher, D. (2009). The PRISMA statement for reporting systematic reviews and meta-analyses of studies that evaluate health care interventions: explanation and elaboration. Journal of clinical epidemiology, 62(10), e1-e34.

Loi, K. I., \& Kong, W. H. (2017). Tourism for all: challenges and issues faced by people with vision impairment. Tourism Planning \& Development, 14(2), 181-197.

Lyu, S. O. (2017). Which accessible travel products are people with disabilities willing to pay more? A choice experiment. Tourism Management, 59, 404-412.

Marpsat, M., \& Razafindratsima, N. (2010). Survey methods for hard-to-reach populations: introduction to the special issue. Methodological Innovations Online, 5(2), 3-16.

Mason, M. (1990). Disability Equality in the Classroom-a human rights issue. Gender and Education, 2(3), 363-366.

Mayordomo-Martínez, D., Sánchez-Aarnoutse, J. C., Carrillo-de-Gea, J. M., García-Berná, J. A., Fernández-Alemán, J. L., \& García-Mateos, G. (2019). Design and Development of a Mobile App for Accessible Beach Tourism Information for People with Disabilities. International journal of environmental research and public health, 16(12), 2131.

McCabe, S., (2020). 'Tourism for all'? Considering Social Tourism: a perspective paper, Tourism Review, 75(1), 61-64.

McCabe, S., Minnaert, L., \& Diekmann, A. (Eds.). (2011). Social tourism in Europe: Theory and practice (Vol. 52). Bristol: Channel View Publications.

McKercher, B., Darcy, S., (2018). Re-conceptualizing barriers to travel by people with disabilities, Tourism Management Perspectives, 26, 59-66

McKercher B, Packer T, Yau MK \& Lam P. (2003). Travel agents as facilitators or inhibitors of travel: perceptions of people with disabilities. Tourism Management, 24(4), 465-474.

Michopoulou E \& Buhalis D (2013). Information provision for challenging markets: The case of the accessibility requiring market in the context of tourism. Information $\mathcal{E}$ Management, 50(5), 229239.

Michopoulou, E., Darcy, S., Ambrose, I., \& Buhalis, D. (2015). Accessible tourism futures: the world we dream to live in and the opportunities we hope to have. Journal of Tourism Futures, 1(3), 179-188.

Mills, J. E., Han, J. H., \& Clay, J. M. (20o8). Accessibility of hospitality and tourism websites: a challenge for visually impaired persons. Cornell Hospitality Quarterly, 49(1), 28-41.

Mitchell, D. T. and Snyder, S.L. (Eds.) (1997) The Body and Physical Difference: Discourses of Disability. Michigan: The University of Michigan Press.

Moura, A. F. A., Kastenholz, E., \& Pereira, A. M. S. (2018). Accessible tourism and its benefits for coping with stress. Journal of Policy Research in Tourism, Leisure and Events, 10(3), 241-264.

Mulrow, C. D. (1994). Systematic reviews: rationale for systematic reviews. British Medical Journal, 309(6954), 597-599.

Murray, M., \& Sproats, J. (1990). The disabled traveller: Tourism and disability in Australia. Journal of Tourism Studies, 1(1), 9-14.

Navarro, S., Andreu, L., \& Cervera, A. (2014). Value co-creation among hotels and disabled customers: An exploratory study. Journal of Business Research, 67(5), 813-818.

Nyanjom, J., Boxall, K., \& Slaven, J. (2018). Towards inclusive tourism? Stakeholder collaboration in the development of accessible tourism. Tourism Geographies, 20(4), 675-697.

Oakes, T., \& Minca, C. (2008). Tourism, modernity, and postmodernity. In Lew, A. A., Hall, C. M., \& Williams, A. M. (Eds.). A companion to tourism. John Wiley \& Sons, p. 280.

Oliver, M. (1990). The Politics of Disablement. Basingstoke: Macmillan.

Oliver M. (2013). The social model of disability: thirty years on. Disability E Society, 28(7), 1024-1026. 
Packer, T. L., Packer, T. L., Mckercher, B., \& Yau, M. K. (2007). Understanding the complex interplay between tourism, disability and environmental contexts. Disability and Rehabilitation, 29(4), 281292.

Packer, T., Small, J., \& Darcy, S. (2008). Tourist experiences of individuals with vision impairment. Queensland: CRC for Sustainable Tourism Pty Ltd.

Pagán, R. (2012). Time allocation in tourism for people with disabilities. Annals of Tourism Research, 39(3), 1514-1537.

Pagán, R. (2015). The contribution of holiday trips to life satisfaction: the case of people with disabilities. Current Issues in Tourism, 18(6), 524-538.

Pahlevan-Sharif, S., Mura, P., \& Wijesinghe, S. N. (2019). A systematic review of systematic reviews in tourism. Journal of Hospitality and Tourism Management, 39, 158-165.

Patterson, I., Darcy, S., \& Mönninghoff, M. (2012). Attitudes and experiences of tourism operators in Northern Australia towards people with disabilities. World Leisure Journal, 54(3), 215-229.

Petersen, A. R., \& Bunton, R. (Eds.). (1997). Foucault, health and medicine. London: Routledge.

Pfeiffer, D. (1993). The problem of disability definition: Commentary. Journal of Disability Policy Studies, 4(2), 77-82.

Poria Y, Reichel A \& Brandt Y (2010). The flight experiences of people with disabilities: an exploratory study. Journal of Travel Research, 49(2), 216-227.

Poria Y, Reichel A \& Brandt, Y (2011). Dimensions of hotel experience of people with disabilities: an exploratory study. International Journal of Contemporary Hospitality Management, 23(5), 571-591.

Pühretmair F. (2004) It's Time to Make eTourism Accessible. In: Miesenberger K., Klaus J., Zagler W.L., Burger D. (eds.) Computers Helping People with Special Needs. ICCHP 2004. Lecture Notes in Computer Science. Heidelberg: Springer. vol 3118.

Pühretmair, F., \& Nussbaum, G. (2011). Web design, assistive technologies and accessible tourism. In Buhalis, D., \& Darcy, S. (Eds.) Accessible Tourism Concepts and Issues. Bristol: Channel View Publications.

Ray N.M. \& Ryder M.E. (2003). "Ebilities” tourism: an exploratory discussion of the travel needs and motivations of the mobility-disabled. Tourism Management, 24(1), 57-72.

Richards, V., Pritchard, A., \& Morgan, N. (2010). (Re) Envisioning tourism and visual impairment. Annals of Tourism Research, 37(4), 1097-1116.

Rucci, A.C., Darcy, S., Garbero, N., Almond, B. (2019). Critical elements in accessible tourism for destination competitiveness and comparison: Principal component analysis from Oceania and South America. Tourism Management, 75, 169-185.

Shakespeare T \& Watson N (1997). Defending the social model. Disability \& Society, 12(2), 293-300.

Shaw G \& Coles T (2004). Disability, holiday making and the tourism industry in the UK: a preliminary survey. Tourism Management, 25(3), 397-403.

Shi L, Cole, S \& Chancellor, HC (2012). Understanding leisure travel motivations of travelers with acquired mobility impairments. Tourism Management, 33(1), 228-231.

Small, J. (2015). Interconnecting mobilities on tour: Tourists with vision impairment partnered with sighted tourists. Tourism Geographies, 17(1), 76-90.

Small, J., Darcy, S., \& Packer, T. (2012). The embodied tourist experiences of people with vision impairment: Management implications beyond the visual gaze. Tourism Management, 33(4), 941950.

Smith, R. W. (1987). Leisure of disable tourists: barriers to participation. Annals of Tourism Research, 14(3), 376-389.

Stoddart, M. C. (2007). Ideology, hegemony, discourse: A critical review of theories of knowledge and power. Social Thought E Research, 28, 191-225. 
Stumbo, N. J., \& Pegg, S. (2005). Travelers and tourists with disabilities: a matter of priorities and loyalties. Tourism Review International, 8(3), 195-209.

Swain, J., French, S., Barnes, C., \& Thomas, C. (Eds.). (2013). Disabling barriers-enabling environments. Sage.

Sydor, A. (2013). Conducting research into hidden or hard-to-reach populations. Nurse Researcher, 20(3), 33-37.

Tchetchik, A., Eichhorn, V., \& Biran, A. (2018). 'Not on my vacation': service encounters between ablebodied and disabled consumers-the case of high-contact service. Journal of Policy Research in Tourism, Leisure and Events, 10(3), 1-17.

Thomson, R. G. (1997) Extraordinary Bodies: Figuring Physical Disability in American Culture in Literature. New York: Columbia University Press.

Tranfield, D., Denyer, D., \& Smart, P. (2003). Towards a methodology for developing evidence-informed management knowledge by means of systematic review. British journal of management, 14(3), 207222.

Tsai CY (2010). The physical disabilities' travel behaviors. African Journal of Business Management, 4(4), 512.

Turco DM, Stumbo N \& Garncarz J (1998). Tourism constraints for people with disabilities. Parks and Recreation-West Virginia, 33(9), 78-85.

Union of the Physically Impaired against Segregation (UPIAS) (1975). Fundamental principles of disability. London: UPIAS.

UNWTO (1980) Manila Declaration on World Tourism. UNWTO. URL:https://www.eunwto.org/doi/pdf/10.18111/unwtodeclarations.1980.01.01 (accessed on 5.12.2019)

UNWTO (1999). Global code of ethics for tourism. UNWTO. URL: https://www.unwto.org/global-codeof-ethics-for-tourism (accessed on 5.12.2019)

UNWTO (2016). Manual on Accessible Tourism for All: Principles, Tools and Best Practices. UNWTO Publications.

Vila, T. D., Darcy, S., \& González, E. A. (2015). Competing for the disability tourism market: a comparative exploration of the factors of accessible tourism competitiveness in Spain and Australia. Tourism Management, 47, 261-272.

Vila, T. D., González, E. A., \& Darcy, S. (2019). Accessibility of tourism websites: the level of countries' commitment. Universal Access in the Information Society, 19(2), 1-16.

Waitzkin, H. (1989). A critical theory of medical discourse: Ideology, social control, and the processing of social context in medical encounters. Journal of Health and Social Behavior, 30(2), 220-239.

Werner, J., Kempf, F. M., \& Corinth, T. (2019). Can You Hear Me? A Research of Touristic Demand from and Supply for Deaf Travelers. In Corporate Sustainability and Responsibility in Tourism (pp. 7995). Springer, Cham.

World Health Organization (1980). International classification of impairments, disabilities, and handicaps: a manual of classification relating to the consequences of disease, published in accordance with resolution WHA29.35 of the Twenty-ninth World Health Assembly, May 1976. World Health Organization. URL: https://apps.who.int/iris/handle/10665/41003 (Accessed on 5.12.2019)

World Health Organization (2001). International Classification of Functioning, Disability and Health (ICIDH-2). Wolrd Health Organization. URL: https://apps.who.int/iris/bitstream/handle/ 10665/42407/9241545429.pdf?sequence=1 (Accessed on 20.01.2020)

World Health Organization (2002) Towards a Common Language for Functioning, Geneva: Disability and Health ICF.

World Health Organization. (2019). Disabilities. WHO URL: http://www.who.int/topics/disabilities. (Accessed on 4.4.2019) 
Yau, MKS, McKercher B \& Packer T. (2004). Traveling with a disability: More than an access issue. Annals of Tourism Research, 31(4), 946-96o.

Zajadacz, A. (2014). Sources of tourist information used by Deaf people. Case study: the Polish Deaf community. Current Issues in Tourism, 17(5), 434-454.

Received: 06/04/2020

Accepted: 26/o9/2020

Coordinating editor: Marko Peric 